British Journal of Nutrition (2021), 126, 1611-1625

doi:10.1017/S0007114521000556

(C) The Author(s), 2021. Published by Cambridge University Press on behalf of The Nutrition Society. This is an Open Access article, distributed under the terms of the Creative Commons Attribution licence (http://creativecommons.org/licenses/by/4.0/), which permits unrestricted re-use, distribution, and reproduction in any medium, provided the original work is properly cited.

\title{
DNA methylation as a regulator of intestinal gene expression
}

\author{
R. M. Pinho* and E. A. Maga \\ Department of Animal Science, University of California, Davis, CA 95616, USA \\ (Submitted 19 June 2020 - Final revision received 21 December 2020 - Accepted 8 February 2021 - First published online 15 February 2021)
}

\section{Abstract}

The intestinal tract is the entry gate for nutrients and symbiotic organisms, being in constant contact with external environment. DNA methylation is one of the keys to how environmental conditions, diet and nutritional status included, shape functionality in the gut and systemically. This review aims to summarise findings on the importance of methylation to gut development, differentiation and function. Evidence to date on how external factors such as diet, dietary supplements, nutritional status and microbiota modifications modulate intestinal function through DNA methylation is also presented.

\section{Key words: DNA methylation: Intestines: Nutritional status: Diet}

Epigenetics refers to the regulation of gene expression through processes that do not change DNA sequence. These changes usually occur in response to environmental conditions and are inheritable through cell division. DNA methylation is the most studied and most common epigenetic modification, influencing gene expression when reduced in promoter regions, the binding site of enzymes responsible for transcription, and increased in the body and 3' end of genes ${ }^{(1)}$. In vertebrates, this is represented by a methyl group covalently bound to the carbon at the 5 , position of the pyrimidine ring of 5-methylcytosine $(5 \mathrm{mC})$ in a CpG dinucleotide (a cytosine followed by a guanine). Genome CpG density is low, with the majority of $\mathrm{CpG}$ being present in CpG islands (CGI) that are on average 1000 bp long ${ }^{(2)}$ and have a relatively high concentration of hypomethylated CpG dinucleotides.

Approximately $70 \%$ of annotated promoters are associated with $\mathrm{CGI}^{(3-5)}$, including promoters of tissue-specific genes and developmental regulators ${ }^{(6,7)}$, with around $50 \%$ of the CGI in mice and humans located in transcription start sites ${ }^{(8)}$. While the functionality of dynamic methylation patterns of the CGI has been more associated with repression of transposons (DNA sequences capable of moving from one location to another within the genome) and repetitive elements, imprinting (selective monoallelic expression), $\mathrm{X}$-inactivation (inactivation of one copy of the $\mathrm{X}$ chromosome in females) and promoter accessibility to transcription factors (TCF) ${ }^{(9)}$, most DNA methylation patterns are probably not biologically functional, making it difficult to create a causation link between DNA methylation, transcriptional activation and gene expression ${ }^{(5,10)}$. However, most CGI promoters are protected against de novo methylation indicating a functional reason for its maintenance in a hypomethylated state. This is corroborated by the embryonic lethality of the knockout (KO) of the DNA methyltransferase (DNMT) genes Dnmt1 or Dnmt3b in mice and the early death of Dnmt $3 a$-KO mice $^{(11,12)}$. The DNMT enzymes are responsible for the establishment and maintenance of methylation patterns on DNA while ten-eleven translocation (TET) enzymes are linked with DNA methylation regulation by catalysing the conversion of $5 \mathrm{mC}$ into 5-hydroxymethylcytosine $(5 \mathrm{hmC})$, which is the first step of the demethylation process ${ }^{(13,14)}$.

In somatic cells, DNA methylation patterns are maintained through inheritance across mitoses with remarkable precision ${ }^{(15)}$ and can even be maintained across generations. However, the maintenance of methylation status is not universal in all genomic regions, as some regions without apparent regulatory functions are heterogeneously methylated even in cell clones ${ }^{(5,10)}$.

The binding of TCF, proteins that regulate transcription, can reduce the methylation level of local and flanking $\mathrm{CGI}^{(4)}$, making it difficult to prove causality between DNA methylation and gene expression. However, the fact that a difference in the methylation pattern reflects modifications of gene expression levels indicates that DNA methylation could be a marker for modification of transcriptional patterns due to environmental changes such as diet and microbiota composition. This review highlights

Abbreviations: BS, bisulphite; CGI, CpG islands; CpG, 5'-cytosine-phosphate-guanine-3'; CV, conventional; DMR, differently methylated regions; DNMT, DNA methyltransferase; GF, germ-free; ISC, intestinal stem cells; KO, knockout; LINE1, long interspersed nuclear element 1; MD, methyl donor; MSP, methylationspecific PCR; TCF4, transcription factor 4; TET, ten-eleven translocation; TLR4, toll-like receptor 4; 5hmC, 5-hydroxymethylcytosine; 5mC, 5-methylcytosine.

* Corresponding author: R. M. Pinho, email rdpinho@ucdavis.edu 
evidence on how nutritional status, diet and microbiota influence intestinal functionality through DNA methylation (Fig. 1), including methodologies used to measure DNA methylation in intestinal tissue, links between DNA methylation and intestinal development, differentiation and maturation and the influence of microbiome modulation on the intestinal methylome.

\section{Methodologies for the analysis of DNA methylation}

Multiple methodologies have been used for the analysis of DNA epimodifications. As genome-wide approaches have become more viable and feasible due to improvements in DNA sequencing technology and analysis, epigenetic modification methodologies have also evolved to high-throughput technologies with single-base resolution.

The most used approaches for methylation profiling target one or a few genomic loci. Identifying CpG methylation on a sequence of defined length is frequently done by methylationspecific PCR (MSP) ${ }^{(16)}$ or pyrosequencing ${ }^{(17)}$. With either methodology, the DNA is first treated with bisulphite (BS) for the conversion of unmethylated cytosines into uracil and subsequently into thymines, which allows the identification of differently methylated loci ${ }^{(18)}$. MSP utilises primers, small oligonucleotides complementary to the targeted region, that are specific for a methylated or unmethylated locus and the presence of a band determines the methylation status ${ }^{(16)}$. One drawback is that only the region of the primers can be truly analysed and a CpG rich region is necessary to create primers specific enough to differentiate between methylated and unmethylated DNA. In BS pyrosequencing, the amplicon sequence can be analysed, which makes it a more quantitative and robust technique than MSP. Pyrosequencing entails sequencing-by-synthesis using pyrophosphate release to identify the nucleotide added to the sequence and therefore can quantify the ratio between cytosines and thymines at a given CpG position. It has also been extensively used as a validation technique for high-throughput methods $^{(19-25)}$. MS-based approaches can also be used to analyse the methylation level at targeted regions ${ }^{(26)}$.

Global methylation quantification is the measure of the general level of DNA methylation without considering methylation changes at specific loci. Different techniques are used to investigate global methylation levels, such as pyrosequencing of Alu or long interspersed nuclear element 1 (LINE1) elements, luminometric methylation assay and HPLC. PCR-based methods estimate the methylation status of the most prevalent repetitive elements in the genome, Alu and LINE1, by pyrosequencing, where the cytosines:thymine ratio at a given CpG in LINE/Alu elements indicates the methylation status. Luminometric methylation assay uses the ratio of the digestion of unsensitive:sensitive isoschizomers to estimate the methylation status. Pyrosequencing LINE1 elements showed the smallest variation between samples and corresponded the best to results obtained by HPLC which is one of the most accurate methods to assess methylation $^{(27)}$. However, caution must be used in extrapolating evidence of methylation changes in LINE1 elements to global changes in specific conditions ${ }^{(28)}$. High performance capillary electrophoresis and chromatography approaches separate methylated and unmethylated DNA by size, and both are quantified, but despite being considered the gold standard for methylation quantification, they usually require a large amount of $\mathrm{DNA}^{(29,30)}$. MS also has high sensitivity and requires lower amounts of starting material ${ }^{(31,32)}$

For genome-wide methylation analysis, although microarraybased methodologies have been used extensively, they require whole genome amplification, which can insert sequence bias, and previous knowledge of the sequence for probe synthesis, but are much more cost-effective than next-generation sequencing approaches ${ }^{(33)}$. This method has been progressively replaced by whole genome bisulphite sequencing (MethylC-seq) that now is considered the gold standard approach and can identify differently methylated regions (DMR) with single bp resolution. Whole genome bisulphite sequencing is done by sequencing of the whole genome after BS treatment and only one of the strands is analysed, although alternative protocols can analyse all four strands formed after the BS treatment ${ }^{(34)}$.

The use of techniques to enrich samples with methylated cytosines or CpG-rich regions of the genome can be used together with genome-wide approaches such as microarrays or next-generation sequencing. The use of beads that have high affinity to $5 \mathrm{mC}$ to precipitate methylated regions (methylated DNA immunoprecipitation) of the genome ${ }^{(35)}$ is one enrichment technique. Methyl binding domain proteins can also be used to enrich methylated genome regions and although it can be used to compare regions between samples, it cannot assess single nucleotide methylation status ${ }^{(36,37)}$.

The use of methylation-sensitive discordant isoschizomers can be used in conjunction with microarrays and sequencing, in, for example, the HpaII tiny fragment enrichment by ligation-mediated PCR (HELP) assay and reduced representation bisulphite sequencing, respectively, usually with the intent to enrich CpG containing areas. The HELP assay ${ }^{(38)}$ has also been used together with sequencing, and in this way it has similar CpG coverage to reduced representation bisulphite sequencing. HELP-tagging is a modification of the methyl-sensitive cut counting assay that uses the HpaII restriction enzyme, with a normalisation step using reads formed by non-methylation-sensitive MspI cleavage. This approach works for CpG rich sites, as well as more $\mathrm{CpG}$ depleted regions in the genome, and compares reads formed by MspI or HpaII digestion to estimate the methylation at each of these sites ${ }^{(39)}$.

Reduced representation bisulfite sequencing ${ }^{(40-42)}$ uses restriction enzymes that have its recognition site in CpG dinucleotides and is insensitive to methylation (usually $\mathrm{MspI}$ ); therefore, each fragment will contain two CpG (one on each end). After digestion and size selection of the fragments, the samples are BS treated to convert unmethylated cytosines into thymines and then sequenced. Reduced representation bisulphite sequencing is one of the most popular methylation assay techniques because it can be used to analyse $80 \%$ of the CGI and $60 \%$ of the promoters ${ }^{(43)}$. But as the other BS-based methods, it cannot distinguish between methylcytosine and hydroxymethylcytosine. A more complete review on these and other methods for methylation analyses can be found at Tost and Gut ${ }^{(44)}$. 


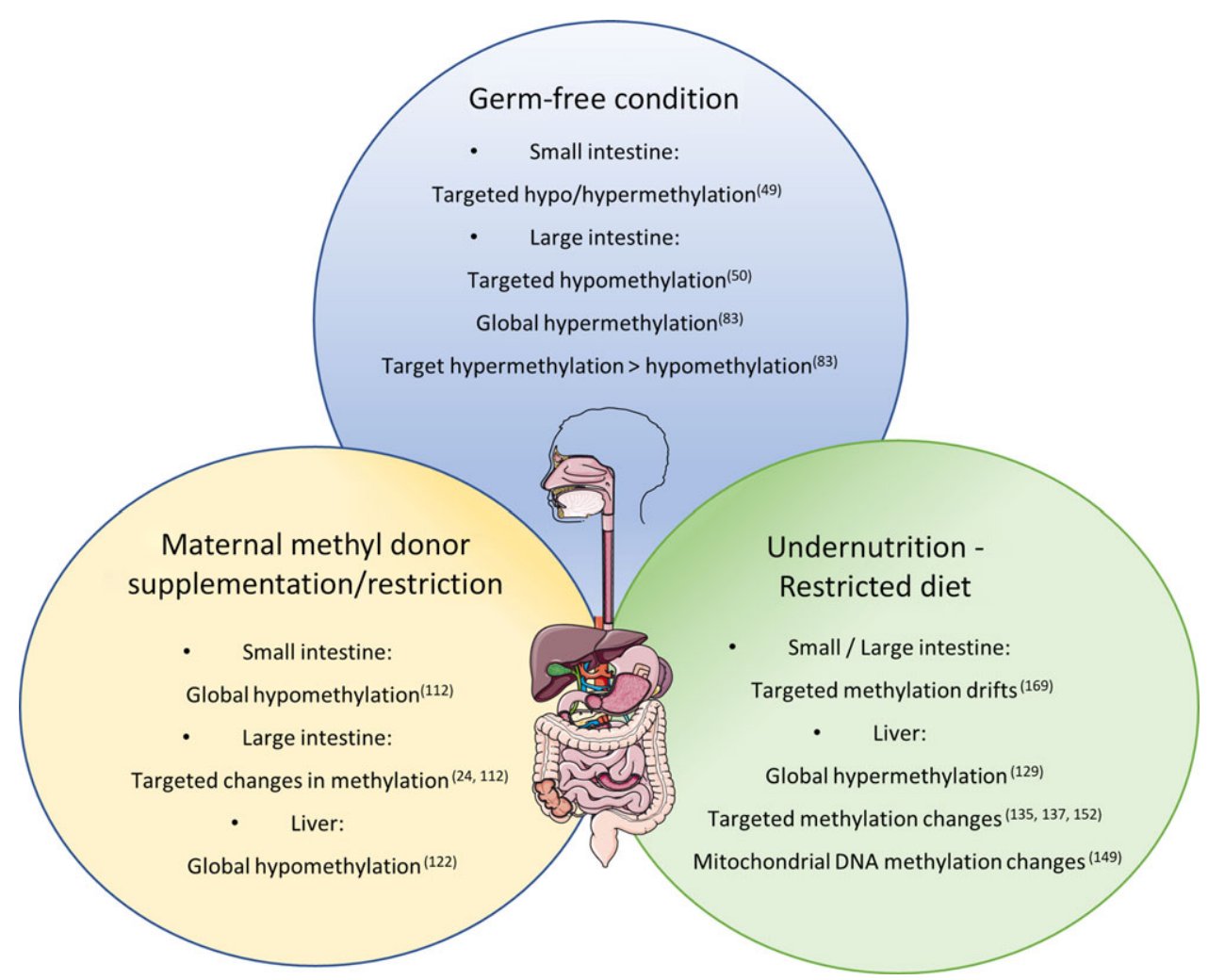

Fig. 1. Nutritional and microbial impacts on DNA methylation of the gastrointestinal tract.

\section{DNA methylation and intestinal development and proliferation maintenance}

The intestinal tract is the organ in mammals responsible for digestion of food for nutrient extraction and absorption and for excretion of digestion and metabolic waste. It is exposed to the external environment and is in constant and intimate contact with micro-organisms in a symbiotic manner.

The small intestine, where most nutrients are absorbed under neurological and endocrine regulation, is a hollow tube lined by a mucosal layer consisting of a single layer of epithelial cells that are the physical barrier between the commensal bacteria and the interior of the host body. These epithelial cells are a heterogeneous population and are being constantly renewed by the division of intestinal stem cells (ISC) located in the intestinal crypts. Other self-renewal cell populations, such as haematopoietic stem cells, have been shown to have progressive changes in DNA methylation in a cell-specific manner ${ }^{(45)}$.

Intestinal development undergoes transitional stages before and after birth, with the postnatal period being crucial for proper intestine and immune system maturation in response to microbial colonisation, oral nutrition, weaning and nutrient availability $^{(46-49)}$. Differences in both gene expression and DNA methylation patterns in the intestines were observed during the transitions between fetal, suckling, weaning and adult life periods ${ }^{(46,50)}$, and differences between intestinal sections in response to maturation were also observed. Regional identity between the different intestinal sections has also been linked to stable DNA methylation signatures observed in paediatric and adult human intestinal epithelial organoids, with fetalderived organoids presenting dynamic methylation changes suggestive of in vitro maturation ${ }^{(51)}$. Notably, most genes that are differentially expressed at the transcriptional level between the suckling and weaning periods stabilise expression levels after weaning, suggesting that early life transitional states can influence gene expression in adult intestines ${ }^{(46)}$. Intrauterine growth restriction can also cause DNA methylation abnormalities $^{(52)}$, which could contribute to the gastrointestinal dysfunctions presented by infants with very low birth weight.

Crypts are responsible for cell proliferation and turnover rate of the intestines and go through maturation in the early postnatal period. Using Dnmt1 KO mice, Yu et al. observed a large variance in the methylome of colonic stem cells of intestinal crypts in mice during the suckling period, especially during maturation, the transition from fetal ISC to adult ISC, compared with differentiation, when the stem cell is turned into different types of epithelial cells ${ }^{(50)}$. The methylation occurred mainly as hypermethylation in CGI associated with gene bodies and the 3 ' end of genes. Dnmt1 KO mice presented severe intestinal abnormalities and an $80 \%$ mortality rate, indicating that DNA methylation is indeed important to intestinal maturation and that dysregulation of methylation patterns in the early postnatal period can lead to an immature intestinal tract. Furthermore, the reduced methylation at the 3 ' end of genes in the KO mice was associated with reduced gene expression. Corroborating with the study of Yu et al., Forn et al., using amplification of inter methylated sites sequencing (AIMS-Seq), found only few 
differences (only $1.65 \%$ of the amplicons) between differentiated villi cells and ISC in the small intestines of mice with hypermethylation being the vast majority of the changes ${ }^{(53)}$.

Other studies have demonstrated the importance of DNMT1 and methylome establishment during the normal maturation and differentiation processes of ISC, confirming differences between methylomes during maturation and differentiation ${ }^{(54,55)}$. They observed a tendency for decreased methylation during differentiation and that DMR were enriched at CGI and CpG shores with the majority (61\%) of DMR hypomethylated during differentiation being at intronic regions. A correlation between loss of methylation in promoter, 3 ' untranslated region and first intron and increased expression level was observed, occurring mainly in genes associated with small intestine metabolism.

The DMR that gain methylation through differentiation were associated with signalling pathways important to ISC function such as wingless and Int-1 signalling pathways (Wnt) and overlap with binding sites for transcriptional factors in ISC such as caudal type homeobox $2(\mathrm{CDX} 2)^{(55)}$. Sheaffer suggests that hypomethylation coordinates the binding of TCF; however, Bestor et al. and others ${ }^{(56,57)}$ propose that the binding of transcriptional factors causes the hypomethylation on the motif regions. Kaaij et al. also related the binding of a TCF with hypomethylation, in this case TCF4, which the author suggests contributes to DMR formation during differentiation of small intestine leucine-rich repeat-containing receptor 5 positive cells (Lgr5+ cells), a marker of ISC ${ }^{(58)}$. Comparing fetal and paediatric intestinal epithelial cells, Kraiczy et al. found that in human ileum and colonic cells, the potentially regulatory DMR frequently overlap transcription start sites and that these DMR were enriched in pathways involved with embryonic, tissue and intestine development. In regulatory DMR-associated genes, the expression was inversely related to promoter DNA methylation. Age was also inversely related to methylation of innate immunity genes and positively correlated with those genes' expression levels.

Differences in methylation level in enhancers and promoters of genes related to ISC function were observed and although intestinal DNMT1 ablation in adult mice intestines can cause alternative methylation patterns in enhancers and delay the differentiation process (by extension of the cryptic zone), it seems to have milder effects compared with early life $\mathrm{KO}^{(50,54,55,58)}$. Perinatal ablation of DNMT1 caused loss of nascent villi due to hypomethylation and premature differentiation and apoptosis ${ }^{(54)}$ due to DNA damage and genomic instability in progenitor cells linked to hypomethylation. Corroborating this, genes associated with cell cycle were expressed at lower levels in the DNMT1-/- ablated cells along with up-regulation of $\mathrm{P} 21$, a gene expressed due to DNA damage and associated with cell cycle arrest ${ }^{(54)}$. Interestingly, Kaaij et al. could not find many DMR in transcription start sites due to differentiation of Lgr5+ inter villi epithelial cells in adult intestines. Instead, they observed that there was considerably stable methylation status between the two cell types, which could corroborate the fact that DNMT-1 and de novo methylation is more important during development than differentiation, hence the milder effects of DNMT1 in adult mice and stabilisation of gene expression after weaning.
Elliott et al. investigated the milder effect of Dnmt1 KO in adult mice and found that it was being compensated for by a higher expression of Dnmt $3 b$ within 2 months of Dnmt1 KO, and that a KO of both Dnmt1 and Dnmt3b in intestines causes high mortality in adult mice, indicating compensatory process $^{(59)}$.

These results were then validated in vitro where perinatal organoid formation and maintenance required DNMT1 but this was not true for organoids from adult crypts ${ }^{(59)}$. Another interesting result in this paper was the increase in expression of the Lysozyme 1 and 2 genes in the Dnmt1-/- intestinal cells compared with wild-type controls. This indicates a premature differentiation of Paneth cells. In addition, other genes related to Paneth cells were up-regulated in the mutant cells. However, staining did not corroborate these findings since few cells in progenitor regions were differentiated. The effect of methylation in Paneth cells might indicate a slow ongoing process instead of a fast morphophysiological modification. In contrast, studies addressing DNA methylation and ageing surprisingly found many genomic regions associated with genes that gained or lost methylation in the intestines over time in humans ${ }^{(20,60)}$ and that some of these patterns are partially conserved in mice in spite of their short lifespan ${ }^{(20,22)}$. Methylome alterations due to ageing in colonic epithelium were also related to greater susceptibility to inflammatory bowel disease in young adults ${ }^{(22)}$. Due to extensive references on the connection between inflammatory bowel disease and DNA methylation, we will not comment on this topic in this review, focusing instead on the impact of dietary supplementation and nutritional status in the intestinal methylome.

Studies focusing on smooth muscle cells have also demonstrated a critical role of DNA methylation on their differentiation, phenotype and expression patterns ${ }^{(61-63)}$. Jorgensen et al., in particular, demonstrated that smooth muscle cell-specific KO of Dnmt1 in mice led to $20 \%$ reduction in global methylation and loss of mature smooth muscle cells. Furthermore, the KO animals presented shorter intestines and a rapid postnatal intestinal dilation beginning at day 10 after birth and leading to death on day 21 by intestinal ischaemia or perforation. They also observed a reduction in expression of TET family genes while DNMT3A protein increased, suggesting a compensatory effect similar to what was observed in other cell types ${ }^{(59)}$.

Not only DNMT are responsible for methylation pattern regulation. TET1, which mediates the demethylation process by conversion of $5 \mathrm{mC}$ into $5 \mathrm{hmC}$, was also studied as a possible ISC methylation regulator during development. Comparing Lgr5+ and differentiated villi cells, the levels of $5 \mathrm{hmC}$ were much higher in progenitor cells in genes associated with Wnt signalling and in ISC markers such as Olfm4 and Lgr $5^{(64)}$. Genes that were expressed only in differentiated cells presented high levels of $5 \mathrm{hmC}$ in villi cells. Interestingly, the differentiated cells had an 8 -fold increase in the total $5 \mathrm{hmC}$ level compared with the Lgr5+ cells. The expression level of Tet 1 was much higher in Lgr5+ cells compared with differentiated cells and the opposite was true for the Tet 2 and Tet 3 genes. Using Tet 1 mutant mice, it was shown that the mutant mice were growth retarded and that the mutation caused significant lethality in the early postnatal period compared with wild-type littermates ${ }^{(64)}$. Also, in the 
intestinal tissue, villi height and the number of progenitor cells in the crypts were significantly reduced in the Tet1-/- mice, indicating that the Tet 1 gene is important for cell proliferation. Organoid budding and size were also decreased in the cultures derived from Tet1-/- intestines. Overall, 5hmC enrichment at the Wnt target site is essential for gene expression of Wnt target genes in Lgr5+ cells and that the depletion of the Tet1 gene product decreased the level of $5 \mathrm{hmC}$ and therefore decreased the expression level of those genes. The conversion of the $5 \mathrm{mC}$ into $5 \mathrm{hmC}$ is an important regulatory mechanism for the expression of Wnt target genes during intestinal postnatal maturation. Kraiczy et al. observed that Tet1 gained methylation and reduced expression through development ${ }^{(19)}$.

A recent study investigating $5 \mathrm{hmC}$ observed dynamic changes during differentiation of mouse progenitor adult ISC into epithelium specialised cells ${ }^{(65)}$. Interestingly, $5 \mathrm{hmC}$ in progenitors did not correlate with transcripts levels while a positive $5 \mathrm{hmC} \times$ gene expression correlation was observed after differentiation. Furthermore, $\sim 60 \%$ of the $5 \mathrm{hmC}$ were intragenic and $5 \%$ of the intergenic $5 \mathrm{hmC}$ were located with $5 \mathrm{~kb}$ of a transcription start site with the gain of $5 \mathrm{hmC}$ upon differentiation occurring mainly in intergenic regions. Gene ontology analysis of the genes containing significant changes in $5 \mathrm{hmC}$ was enriched for cell metabolism and cell-cell interaction while intergenic $5 \mathrm{hmC}$ was assigned to the closest gene and those were enriched for organ morphogenesis, cell signalling and DNA template processes.

Overall, the importance of DNA methylation on early life intestinal development is notable. The regulation of intestinal maturation is being driven at least in some part by DNA methylation with the differentiation process being less dependent on methylation modifications. Also, it is interesting to note the association between methylation level differences during the growth/ageing processes, mostly with hypomethylation either locally in the first case or globally in the later.

\section{Microbiota composition influence on intestinal DNA} methylation and development and 'functionality'

Intestinal commensal bacteria colonisation in the postnatal period influences physiology, morphology and functionality of the intestinal tissue ${ }^{(66,67)}$ and can affect gene expression of the host, as shown in many studies comparing germ-free (GF) and conventionally raised animals ${ }^{(68-72)}$ and reviews on the topic ${ }^{(66,73,74)}$. The link between microbiota and intestinal renewal has also been found in species that have historically less evidence of DNA methylation such as Drosophila ${ }^{(75)}$, indicating that DNA methylation status may be an acquired regulation during evolution. Also, epigenetic reprogramming of host genes has been demonstrated during microbial and virus infections and has been associated with malignant progression of cancer ${ }^{(76,77)}$.

Microbiota effects on host physiology can be associated with bacterial metabolites, such as butyrate, a by-product predominantly from Firmicutes metabolism, that potentially influences host gene expression by histone chromatin modifications ${ }^{(78)}$. Fermentation of dietary fibre by bacterial populations in the colon produces butyrate that is the main source of energy to colonocytes. Also, the regulatory function of butyrate as an inhibitor of histone deacetylase is consequently associated with open chromatin and accessibility to transcriptional machinery ${ }^{(79)}$ linking butyrate to increases in gene expression and indirectly to decreases in DNA methylation ${ }^{55,80)}$. Besides butyrate production, intestinal microbiota produce $\mathrm{B}$ vitamins and folate, metabolites that participate in one-carbon metabolism of the host, both as methyl donors (MD) and co-factors, potentially influencing constitution of the methylome since they cannot be synthesised by humans ${ }^{(81)}$.

Corroborating the fact that the lack of bacteria in the intestinal tract can induce methylome modification of the intestinal epithelium, Yu et al. compared identical lines of mice in axenic or conventional (CV) conditions ${ }^{(50)}$. They observed an abnormal DNA methylation profile, specifically hypomethylation of $\mathrm{CpG}$ nucleotides in GF mice at 21 and 100 days of life, while on day 0 , methylation patterns were indistinguishable between GF and CV mice. Interestingly, the hypomethylation was not global and did not affect genome repetitive elements, suggesting a specificity to the regulation of DNA methylation by the intestinal microbiota. Hypomethylated CGI in GF mice were related to lower expression of genes associated with intestinal maturation and that, for some genes, the expression level was increased to levels comparable to $\mathrm{CV}$ mice after the reconstitution of the commensal bacteria by faecal microbiota transplant.

Pan et al. also investigated the influence of microbiota colonisation at different life stages on the methylome of small intestine epithelial cells ${ }^{(49)}$. They observed that the influence of microbial presence on DNA methylation was detected early after birth and global methylation level increased subtlety over time. The number of differently methylated positions between CV and GF animals was ten times greater (1496 differently methylated positions) in the first week after birth than in week 4 and weeks $12 / 16$, which corroborates with the idea that microbial colonisation has great impact on gut function during early life, when differently methylated positions were also enriched in promoter regions. However, adult mice (12/16 weeks) presented greater number of differently expressed genes (79) containing differently methylated positions compared with only 17 in week 1 . Furthermore, both Tet3 and Dnmt3a expression levels were altered by microbiota presence in week 1 and week 12/16 after birth.

Interestingly, the intestinal adaptation of preterm piglets to microbiota colonisation and milk enteral feeding was shown to involve DNA methylation changes and occurred mostly in the first month of life, with the global hypermethylation of preterm intestines observed within the first 5 days of life normalising to the levels of the term intestine by the 26th day after birth ${ }^{(82)}$. Methylation differences observed in the five postnatal days between preterm and term in mid intestine affected Wnt signalling and lipopolysaccharide-binding protein-toll-like receptor 4 (TLR4) pathways, indicating cell proliferation and immune alterations in the preterm gut.

In a more recent study, Ansari et al. observed a global hypomethylation in colonic crypts when comparing CV to GF mice accompanied by a subtle change in gene promoters ${ }^{(83)}$. Analysing low-methylated regions representing potentially active regulatory regions, they observed a greater number of 
hypomethylated low-methylated regions (12 983) in the CV mice with only 3115 hypermethylated when compared with the GF animals. Furthermore, the majority (78.2\%) of low-methylated regions associated with changes in gene expression were hypomethylated and from those, 300 were linked with significantly increased expression and were enriched for the binding sites of forkhead box A, kruppel like factor and activator protein 1 TCF. These findings suggest a much more intricate role of bacteria-host interaction on DNA methylation and regulation of gene expression. It also shows that the microbiota helps to regulate intestinal maturation and homoeostasis through DNA methylation, possibly controlling TCF binding sites.

Takahashi and colleagues observed that the methylation profile of the TLR4 gene was different in CV and GF mice with the 5 end of the gene being considerably hypomethylated in the intestinal epithelial cells of the large intestine of GF mice ${ }^{(84)}$. Interestingly, Tlr4 expression was not associated with its methylation status in the small intestine, suggesting that the bacterial load in large intestine could be an important factor for bacterial regulation of Tlr4 gene expression and that there is a complementary regulatory process for Tlr4 expression in the small intestine.

Both microbiota shifts and difficulties in discriminating commensal from pathogenic bacteria can play a role in regulating host functionality. Host recognition of bacterial populations and its link with DNA methylation, gene expression and host physiology were further corroborated with the use of TLR2 KO mice ${ }^{(23)}$. The Tlr2 KO mice had different expression levels of genes associated with immune response correlated with changes in DNA methylation and were combined with shifts in colonic microbial populations with Firmicutes being less abundant and Proteobacteria and Bacteroidetes more abundant in the KO mice. Interestingly, the diversity was much higher for the bacteria present within the Tlr2 KO mice, compared with the much more closely clustered wild-type samples, indicating a more consistent control of microbiota population diversity by the presence of TLR2.

Interestingly, in a study from Bhat et al., neither probiotics nor E. coli exposure alone alters global DNA methylation in Caco-2 cells despite changes in histone acetylation ${ }^{(85)}$. However, when cells treated with probiotic strains of Lactobacilli were challenged with E. coli, the result was global hypermethylation, indicating that interactions within microbiota populations also influence host functionality.

Although many studies focus on changes in microbiome composition due to different conditions, such as nutritional status (reviewed by Million et al.; Castaner et al.; Blanton et al. $)^{(86-88)}$, diet (reviewed by Singh et al. $)^{(89)}$, antibiotic use (reviewed by Iizumi et al. $)^{(90)}$ and pathological conditions (reviewed by Wang et al. ( $^{(91)}$, only few look for associations between shifts in bacterial populations and DNA methylation status of the host despite observed changes in gene expression. Therefore, new research on the regulatory mechanisms, including DNA methylation, that bacterial populations use to impact host function can help to determine the important microbialhost interactions that influence physiological and pathological processes.

\section{Dietary supplementation and DNA methylation}

The association between diet and the intestinal microbial population has been extensively studied ${ }^{(92,93)}$. Gene expression modifications and epigenetic alterations in different tissues and developmental stages due to host gene expression directly or indirectly associated with diet and nutritional status have also been extensively demonstrated (reviewed by JiménezChillarón et al. $)^{(94)}$. However, the effects of dietary interventions on the intestinal tract epigenome are not well established and the molecular mechanisms regulating the change in transcription level in response to intake modifications or microbiota manipulations have still to be elucidated for a large part of the observed events. For instance, Krautkramer et al. demonstrated that the microbiota induces histone modification in the host tissue, including liver and colon, in a diet-dependent manner, suggesting modulation of bacterial population and function due to nutrient availability ${ }^{(92)}$. This was confirmed by including SCFA to the diet of GF mice and observing a rescue of the expression level and chromatin modification to levels compared with colonised mice.

DNA methylation deposition requires not only the presence of DNMT enzymes but also the presence of methyl groups that are supplied by the one-carbon metabolic pathway (Fig. 2) that is dependent on nutrition ${ }^{(95,96)}$. The major source of methyl groups for multiple cellular methylation processes (DNA, RNA, protein and lipid methylation) through the action of methyltransferases is S-adenosylmethionine, derived from one-carbon metabolism, which is dependent on multiple substrates, factors/co-factors such as $\mathrm{B}_{12}, \mathrm{~B}_{6}$, folate, methionine and betaine ${ }^{(97,98)}$. The intake of some of these nutrients, also known as MD, has been shown to have systemic effects on methylation, such as folate intake restoring methylation status of blood cells of patients with hyperhomocysteinaemia, a disease that characterised by an unbalanced one-carbon cycle that results in global hypomethylation ${ }^{(99)}$.

Early nutritional effects on metabolism and disease predisposition have been observed on multiple occasions and extensively studied $^{(94,100,101)}$. One of the mechanisms by which nutrition can establish these long-lasting modifications is via DNA methylation as shown with the maternal MD supplementation of yellow agouti mice ${ }^{(102)}$. The MD diet altered the coat colour of the offspring due to DNA methylation of the transposable element inserted in the agouti gene, indicating that dietary exposure in pregnancy or early life can have significant and long-lasting effects on metabolism and disease susceptibility in different organs of the offspring including the intestines. Policies for supplementation with folic acid for pregnant women to prevent open neural tube defects ${ }^{(103)}$, the increase in the use of MD supplementation, especially in developed countries, and long-lasting effects of maternal diet on the DNA methylation of the offspring ${ }^{(104-109)}$ encouraged the investigation into transgenerational risks and effects of maternal supplementation with $\mathrm{MD}^{(97)}$.

Morphological changes due to MD supplementation/deficiency have also been observed in the intestines. Silva et al. found sporadic regions throughout the small intestine with increased crypt depth in the offspring of dams submitted to a 


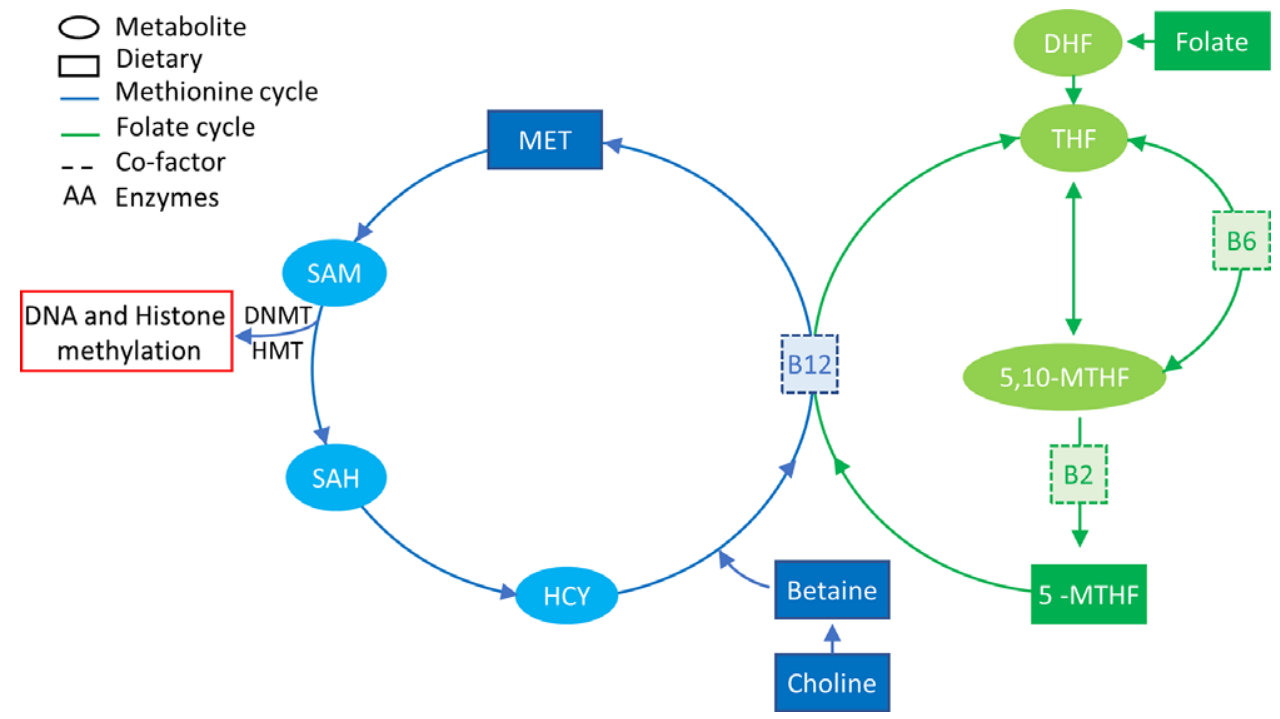

Fig. 2. One-carbon metabolism. The methionine cycle is represented in blue and the folate cycle is represented in green. Square boxes represent nutrients supplied in the diet. Choline and betaine are part of the resource pool of methionine together with homocysteine (HYC). $\mathrm{B}_{12}$ is a co-factor for the conversion of 5-MTHF, which is a result of a series of folate reductions into THF, freeing one methyl group for the conversion of HCY into MET. MET in turn is converted to SAM that donates a methyl group to DNA/histone methylation when it is converted to SAH. 5-MTHF, 5-methyl tetrahydrofolate; 5,10-MTHF, 5,10-methylenetetrahydrofolate; DHF, dihydrofolate; DNMT, DNA methyltransferase; HMT, histone methyltransferase; HYC, homocysteine; MET, methionine; SAH, S-adenosyl homocysteine; SAM, S-adenosyl methionine; THF, tetrahydrofolate.

methyl deficient diet during gestation until weaning ${ }^{(110)}$. The MD deficient offspring also had a decrease in jejunal and faecal microbial $\alpha$-diversity and lower relative abundance of Bacteriodales and higher abundance of Lactobacillales. Interestingly, they also observed target hypomethylation of glycosylation genes in enteroids cultured in methyl deficient media ${ }^{(110)}$. Furthermore, DNA methylation levels of two repetitive elements were measured and only one (IAP) was hypomethylated in the MD deficient enteroids, disregarding global hypomethylation and contradicting the one-carbon metabolism theory.

The one-carbon metabolism theory suggests that a reduced intake of dietary MD would induce a global hypomethylation due to decreased resources for formation of methyl groups, and the opposite would also be true, with an increase in DNA methylation due to a dietary supplementation of MD. This is corroborated by studies like the one from Choi et al., which describe a 35\% reduction in DNA methylation in colonic genome of rats after vitamin $\mathrm{B}_{12}$ deficiency ${ }^{(111)}$, and from McKay et al. that observed global hypomethylation in the small intestine of offspring of dams submitted to a low folate diet during pregnancy and lactation ${ }^{(112)}$

However, local hyper and hypomethylation were observed in studies with MD supplementation contradicting the idea that DNA methylation would decrease or increase in a random, dysregulated manner. Schaible et al., for instance, found that supplementation of the maternal diet with a combination of MD such as $\mathrm{B}_{12}$, folate and choline can alter the establishment of DNA methylation in mice as observed at postnatal day 30 (P30) and $\mathrm{P}^{(24)}$. They observed fifty-nine hypermethylated regions and ninety-six hypomethylated ones, with more than $50 \%$ hypomethylated loci localised on the $\mathrm{X}$ chromosome. The changes in methylation were combined with an increase in the susceptibility to acute colitis induced by dextran sodium sulphate associated with changes in gene expression. Eighteen of the 155 DMR were associated with change in expression of a flanking gene, including the PPAR $\alpha$ gene, which showed decreased methylation level and increased expression. Finally, they also assessed the mucosa-associated microbiome of the offspring and found a significant separation at the genus level at P30 that is rescued by P90 with Bacteroidetes and Clostridia being overrepresented, and Lactobacillus underrepresented in early life of MD-exposed offspring

Maternal diet can also influence the DNA methylation level of the PPAR $\alpha$ promoter in the liver of the offspring ${ }^{(113,114)}$, with protein-restricted diet having $26 \%$ less methylation than the controls and folic acid rescuing the methylation status ${ }^{(114)}$, corroborating with the findings of Schaible et al.. In the murine fetal gut, a low folate maternal diet reduced the methylation in the $\mathrm{Zn}$ transporter gene solute carrier 39 member 4 (Slc39a4), but did not cause changes in the methylation of insulin-like growth factor 2 and oestrogen receptor $1^{(115)}$. Paternal folic acid deficient and supplemented diet throughout life also impacted DNA methylation levels of imprinted genes in the brain and in the placenta and increased postnatal-preweaning pup death ${ }^{(116)}$, as was observed by Ly et al.

Despite the fact the important epigenetic modification occurs in colonic mucosa during paediatric development as shown by Kellermayer et al. ${ }^{(22)}$, Schaible et al. did not observe an increase to colitis susceptibility when the mice were exposed to MD supplementation from P30 to P80, suggesting that the in utero effect is more important than postnatal dietary exposure. These results were in agreement with the findings from Mir et al. that, in spite of not analysing the DNA methylation status, observed a $25 \%$ increase in mortality in the MD group offspring, with males being more susceptible to colitis ${ }^{(117)}$. The sex difference might be 
related to the finding of Schaible et al. that a high percentage of hypomethylated regions due to maternal MD were localised on the X chromosome. Trasler and colleagues also did not observe changes in global methylation in the colon of mice predisposed to intestinal adenoma formation $\left(\mathrm{Apc}^{+/ \mathrm{Min}}\right)$ submitted to a low folate diet from weaning to 13 weeks of age with or without reductions in Dnmt1 expression due to heterozygous gene $\mathrm{KO}^{(118)}$.

It is noteworthy that the impact of methyl deficient/supplemented diets on DNA methylation is organ specific, as observed in studies focusing on liver and brain DNA methylation in rats under dietary restriction of methionine, choline and folic acid. In these studies, global hypomethylation was observed in the liver ${ }^{(119)}$ and genome hypermethylation in the brain ${ }^{(120)}$. Ly et al. 2016 also observed that maternal supplementation with folic acid during the second and third week of gestation or throughout pregnancy decreased global methylation in the brain, while no global alterations were observed in the liver, colon or kidney of the offspring pups ${ }^{(121)}$.

The tumour suppressor gene p53, generally mutated or dysregulated in cancer, showed an increase in DNA methylation in its promoter in liver and colon mucosa following selenomethionine diet supplementation ${ }^{(122)}$. Global DNA methylation was decreased in the liver of rats fed with extra selenomethionine, while the selenomethionine-deficient animals had global hypermethylation. This was not true for colon mucosa, where the selenomethionine intake did not significantly influence global methylation status. Using a modelling approach to identify variables that had the strongest association with gene-specific methylation, Tapp et al. observed greater correspondence between age and methylation level in males than in females and that correlation was weak and slightly negative for LINE-1 elements, indicating a subtle age-related hypomethylation ${ }^{(123)}$. Plasma folate and red cell folate correlated with the methylation of some of the genes in a sex-dependent manner. A similar trend was observed with plasma selenium that presented a positive correlation with methylation in males but a negative correlation in females. Interestingly, neither $\mathrm{B}_{12}$ nor homocysteine had a significant correlation with methylation status.

Other diet supplementations, not directly associated with one-carbon metabolism, have also been shown to influence DNA methylation in intestinal tissue. One example was the association of epigallocatechin-3-gallate, the catechin of green tea, to a regulatory effect on DNMT enzymes ${ }^{(124)}$. It has also been shown to inhibit DNMT in multiple cells including colon cell lines ${ }^{(125)}$. Despite that the majority of epigallocatechin-3-gallate is absorbed in the small intestine, the administration of epigallocatechin-3-gallate resulted in a shift in microbiota population in the colon of mice, resulting in a decrease in acetic and butyric acids $^{(126)}$ suggesting a modulation of energy metabolism. Remely et al. found that the methylation of CGI associated with the promoter region of multL homolog 1 (MLH1) in the colon increased with ECGC intervention to a greater extent than with a high fat diet, with or without ECGC ${ }^{(124)}$. In fact, a high fat diet coupled with ECGC decreased the methylation level of this CGI. Dnmt1 gene expression was lower in the colon of mice fed a high fat diet, but the expression level was rescued when ECCG was added to the diet. CpG in the promoter region of
Dnmt1 were hypermethylated when ECGC was added to either high fat or control diets.

Organ-specific effects were also observed with dietary supplementation of nutrients outside one-carbon metabolism. Day et al. observed DNA methylation changes in the prostate of rats but not in the liver after diet supplementation with the soya phyto-oestrogen genistein ${ }^{(127)}$. This was similar to the findings of Guerrero-Bosagna et al., where continuous pre- and postnatal genistein and daidzein exposure did not alter hepatic methylation level in the promotor region of the gene $\alpha$-actin (Acta1), but it caused hypermethylation in the pancreas ${ }^{(128)}$.

All this evidence suggests that the diet can affect the methylation status systemically and locally in the intestinal tract, representing both a risk and a protective function for specific disease pathologies. The consequences of food and nutrient intake on the molecular mechanisms regulating gene expression and consequently the function of the intestines should be further studied as an easy and affordable way of preventing and treating pathological conditions/states.

\section{Nutritional status and DNA methylation}

Extreme nutritional status, such as undernutrition and obesity, has been reported to influence DNA methylation in different organs with a potential impact on the health of individuals as parental dietary conditions also effect the metabolism and methylation level in offspring. Maternal nutrition has been shown to influence the state of DNA methylation in offspring in several animal models. In rats and mice, it has been reported that maternal malnutrition due to protein deficiency resulted in stable global hypermethylation until adulthood in the liver of the offspring ${ }^{(129)}$. Methylation changes at specific loci in the liver ${ }^{(113,114,130-138)}$, pancreas ${ }^{(139)}$, amygdala ${ }^{(140)}$, adrenal gland $^{(141,142)}$, hypothalamus ${ }^{(143)}$ and adipose tissue ${ }^{(144,145)}$ were also reported correlating with changes in gene expression. Likewise, low protein feeding caused paternal transgenerational effects in mice, including various DNA methylation changes in the offspring's liver ${ }^{(137)}$. In utero undernutrition increased obesity and glucose resistance in mice and interestingly, the female offspring of male mice submitted to in utero undernutrition also developed glucose intolerance which was linked to DNA methylation alteration on the liver $\mathrm{X}$ receptor alpha (Lxr $\alpha$ ) gene in the liver, the same methylation signature found on the sperm of the F1 mice ${ }^{(135)}$. Accordingly, Radford et al. found that in utero undernutrition changes the germline methylome of the male offspring with a prevalence of hypomethylation and enrichment of DMR in nucleosome retaining regions, and part of the alteration is resistant to embryo methylation reprogramming ${ }^{(146)}$. However, Ivanova et al. found that the liver DMR identified in mice treated with maternal or early postnatal protein restriction did not significantly affect imprinted genes, indicating that expression of imprinted genes is not particularly influenced by maternal or early life nutrition ${ }^{(147)}$.

Maternal diet during pregnancy was also shown to impact methylation status in species other than rodents. The offspring of sows under dietary protein restriction during pregnancy developed changes in DNA methylation in CGI flanking 
metabolic genes, such as PPAR $\alpha$, in the liver ${ }^{(148)}$. Maternal lowprotein diet also affected mitochondrial DNA methylation in the liver of piglets ${ }^{(149)}$ and muscle GLUT type 4 (GLUT4) promoter methylation level ${ }^{(150)}$. Energetic restriction in baboons during early pregnancy resulted in global hypomethylation in fetal kidneys and in late gestation resulted in global hypermethylation in fetal kidneys and frontal cortex ${ }^{(151)}$. Hepatic epigenetic modification was also observed in baboon fetus due to maternal malnutrition ${ }^{(152-154)}$. Tobi et al. found hypomethylation at the insulin-like growth factor 2 locus and other genes in leucocytes of women that were affected by famine during the peri-conception period and that the difference of methylation in some of the genes was sex specific ${ }^{(153-157)}$.

Dietary interventions can also influence epigenome changes in early/adult life specially during dietary transitions. Post-weaning malnourishment in mice caused global hypomethylation in the thalamus and hypothalamus with methylation profiling in the thalamus identifying DMR (both hypomethylated and hypermethylated) in genes associated with neuronal development or psychiatric diseases, including nine genes related to long-term potentiation $^{(158)}$. Peter et al. found associations between the blood DNA methylation profile associated with severe malnutrition in early childhood and impairments in attention and cognition $^{(159)}$. A study in India searched for correlation between DNA methylation in LINE1 sites in DNA from blood cells of children from 5 to 12 years old with malnourishment indices such as $Z$-score, BMI and blood vitamin concentration $\left(\mathrm{B}_{12}\right.$ and folic acid) and found that the DNA methylation at LINE1 elements relates inversely to retinol levels in the blood ${ }^{(160)}$.

Ageing is usually associated with global hypomethylation combined with hypermethylation at specific loci, which is also the methylation profile linked to cancer (reviewed by Klutstein et $a l.)^{(161)}$. Energetic restriction can potentially reverse age-related abnormal DNA methylation, increasing genomic stability ${ }^{(162,163)}$ in a possible explanation as to why it is considered the most powerful mechanism to increase lifespan in different animal models ${ }^{(162,164-168)}$. Rhesus monkeys exposed to chronic $30 \%$ energetic restriction had a reduction in the agerelated methylation drift in their blood compared with ad libitum fed controls ${ }^{(169)}$. The same study found that in mice with $40 \%$ energetic restriction, similar but more evident results were observed across multiple tissues. Furthermore, fifteen genes that showed an age-related drift in methylation in the blood of the monkeys were analysed in various tissues including the small and large intestine, and an even larger methylation drift was seen in the large intestine with the selected genes also showing agerelated clustering in both the small and large intestines indicating a marked effect of diet on the DNA methylation profile in these tissues.

High-fat diets and maternal overnutrition and obesity during gestation also influence the DNA methylation levels of the offspring in tissues including the brain ${ }^{(170,171)}$, liver ${ }^{(172-174)}$, blood $^{(175)}$ and adipose tissue ${ }^{(176)}$. Contrastingly, Li et al. found that offspring of obese female mice presented widespread but subtle alterations in their hepatic DNA methylation profile and suggested that healthy postnatal feeding would be enough to prevent metabolic dysfunctions in the offspring ${ }^{(177)}$. This is in agreement with Moody et al. that showed evidence that postnatal diet can reverse the methylation effects in the liver caused by a high fat maternal diet ${ }^{(178)}$. As with undernutrition, in rats, female offspring of high fat-fed males presented with programmed $\beta$ cell dysfunction despite the fact of not being exposed to a high-fat diet during development ${ }^{(179)}$ and the alteration was accompanied by DNA methylation changes. There is also evidence that obesogenic diets combined with obesity-associated microbiome modulate colonic gene expression through epigenetic modifications other than DNA methylation ${ }^{(180)}$. Maternal and paternal obesity have also been associated with DNA methylation changes in fetal blood and placenta at specific $\operatorname{loci}^{(104,177,181,182)}$.

Chronic high-fat diet in mice (from weaning to 20 weeks of age) changed promoter methylation status of genes associated with food intake in brain tissue ${ }^{(170,183)}$, which could explain the establishment of obesity and obesity-related diseases. Neonatal overfeeding has also been associated with changes in DNA methylation in the hypothalamus of rats and was associated with decreased expression of genes associated with the metabolic syndrome ${ }^{(171,184,185)}$. There has also been work relating DNA methylation profiles (especially in blood) with BMI, waist circumference and body composition. In an epigenomewide study using blood samples from human subjects ${ }^{(186)}$, it was observed that validated, differently methylated CpG associated with genes or coding regions explained $14.18 \%$ of the BMI score and $16.73 \%$ of the waist circumference variability. Interestingly, from the 95 loci with CpG significantly associated with BMI, only ten were genes previously associated with BMI from a genome-wide association study. Using blood samples from preschool children, Rzehak et al. found specific DNA methylation variants associated with BMI, fat mass and fat-free $\operatorname{mass}^{(187)}$.

Noticeably, the link between extreme nutritional status and developmental programming has been extensively studied, especially in the liver, brain and adipose tissue, while information regarding the intestines is still lacking. However, if nutritional supplementation and microbiome colonisation have organ-specific effects, it is not farfetched that the effects of obesity and undernutrition in these tissues do not reflect what would be observed in the intestinal tract and the different sections of the small and large intestine.

Although morphophysiological changes in the intestines due to malnutrition have been shown ${ }^{(188)}$, including in swine models for childhood undernutrition ${ }^{(189)}$, the molecular aspects underlying these changes have not been understood. Furthermore, there have been few efforts towards analysing DNA methylation profile changes in the intestines, especially the small intestines, due to extreme nutritional status. As the point of adaptation between nutritional intake and immune protection, changes in the intestinal tract could potentially be related to systemic effects of dietary manipulations. The known effects of nutritional status on the epigenome of the intestinal tract are limited and could be the key to explain how dietary intervention can systemically influence host physiology. 


\section{Conclusions}

It is easy to see how information on the molecular effects of how diet and nutritional status directly influence the intestine and how the interplay between nutrient intake/nutritional status and commensal bacteria influences host health and their longlasting effects on metabolism and disease predisposition is still lacking. The use of diet to manipulate host physiology to better respond to pathological or adverse conditions such as undernutrition, chronic inflammatory diseases and diarrhoea could be used once the mechanisms behind the interactions between diet, microbiota and host are understood. As observed in this review, DNA methylation can help to link environmental shifts to host function, but there is still a long way to go in describing the actions of bioactive nutrients and foods that could benefit host health. The links between intestinal and nutritional biology need to be better defined in order to answer clinically relevant questions. For instance, could diet/microbiota modulation be an effective and precise approach to manipulate intestinal cell function against specific medical conditions? At what stage of life would these alterations need to occur and are they sustainable over time? Specifically, the role of epigenetics as a conductor makes it a crucial point of study to deepen our knowledge of intestinal adaptation to nutritional challenges and discover its translational potential in precession medicine.

\section{Acknowledgements}

We thank the Brazilian National Council for Scientific and Technological Development (CNPq) and the Science without Borders program for financially supporting the author R. M. P. $\mathrm{CNPq}$ had no role in the design, analysis or writing of this article. The authors' responsibilities were as follows: R. M. P. and E. A. M. conceptualized the review topic; R. M. P. collected and curated the data; both authors drafted and reviewed the manuscript; $\mathrm{R}$. M. P. had primary responsibility for the final content; and both authors read and approved the final manuscript.

The authors declare that there are no conflicts of interest.

\section{References}

1. Yu D-H, Ware C, Waterland RA, et al. (2013) Developmentally programmed 3' CpG island methylation confers tissue- and cell-type-specific transcriptional activation. Mol Cell Biol 33, 1845-1858.

2. Deaton A \& Bird A (2011) CpG islands and the regulation of transcription. Genes Dev 25, 1010-1022.

3. Saxonov S, Berg P \& Brutlag DL (2006) A genome-wide analysis of $\mathrm{CpG}$ dinucleotides in the human genome distinguishes two distinct classes of promoters. Proc Natl Acad Sci 103, 1412-1417.

4. Bestor TH, Edwards JR \& Boulard M (2015) Notes on the role of dynamic DNA methylation in mammalian development. Proc Natl Acad Sci 112, 6796-6799.

5. Lister R, Pelizzola M, Dowen RH, et al. (2009) Human DNA methylomes at base resolution show widespread epigenomic differences. Nature 462, 315-322.

6. Larsen F, Gundersen G, Lopez R, et al. (1992) CpG islands as gene markers in the human genome. Genomics 13, 1095-1107.
7. Lokk K, Modhukur V, Rajashekar B, et al. (2014) DNA methylome profiling of human tissues identifies global and tissuespecific methylation patterns. Genome Biol 15, r54.

8. Illingworth RS, Gruenewald-Schneider $\mathrm{U}$, Webb $\mathrm{S}$, et al. (2010) Orphan CpG Islands Identify numerous conserved promoters in the mammalian genome. PLOS Genet 6, e1001134.

9. Edwards JR, Yarychkivska O, Boulard M, et al. (2017) DNA methylation and DNA methyltransferases. Epigenetics Chromatin 10, 23.

10. Edwards JR, O'Donnell AH, Rollins RA, et al. (2010) Chromatin and sequence features that define the fine and gross structure of genomic methylation patterns. Genome Res 20, 972-980.

11. Okano M, Bell DW, Haber DA, et al. (1999) DNA methyltransferases Dnmt3a and Dnmt3b are essential for de novo methylation and mammalian development. Cell 99, 247-257.

12. Li E, Bestor TH \& Jaenisch R (1992) Targeted mutation of the DNA methyltransferase gene results in embryonic lethality. Cell 69, 915-926.

13. Tahiliani M, Koh KP, Shen Y, et al. (2009) Conversion of 5-methylcytosine to 5-hydroxymethylcytosine in mammalian DNA by MLL Partner TET1. Science 324, 930-935.

14. Rasmussen KD \& Helin K (2016) Role of TET enzymes in DNA methylation, development, and cancer. Genes Dev 30, 733-750.

15. Wigler M, Levy D \& Perucho M (1981) The somatic replication of DNA methylation. Cell 24, 33-40.

16. Herman JG, Graff JR, Myohanen S, et al. (1996) Methylationspecific PCR: a novel PCR assay for methylation status of CpG islands. Proc Natl Acad Sci 93, 9821-9826.

17. Tost J \& Gut IG (2007) DNA methylation analysis by pyrosequencing. Nat Protoc 2, 2265-2275.

18. Frommer M, McDonald LE, Millar DS, et al. (1992) A genomic sequencing protocol that yields a positive display of 5-methylcytosine residues in individual DNA strands. Proc Natl Acad Sci 89, 1827-1831.

19. Kraiczy J, Nayak K, Ross A, et al. (2016) Assessing DNA methylation in the developing human intestinal epithelium: Potential link to inflammatory bowel disease. Mucosal Immunol 9, 647-658.

20. Maegawa S, Hinkal G, Kim HS, et al. (2010) Widespread and tissue specific age-related DNA methylation changes in mice. Genome Res 20, 332-340.

21. Harris RA, Nagy-szakal D, Mir SAV, et al. (2014) DNA methylation-associated colonic mucosal immune and defense responses in treatment-naïve pediatric ulcerative colitis. Epigenetics 9, 1131-1137.

22. Kellermayer R, Balasa A, Zhang W, et al. (2010) Epigenetic maturation in colonic mucosa continues beyond infancy in mice. Hum Mol Genet 19, 2168-2176.

23. Kellermayer R, Dowd SE, Harris RA, et al. (2011) Colonic mucosal DNA methylation, immune response, and microbiome patterns in Toll-like receptor 2-knockout mice. FASEB J 25, 1449-1460.

24. Schaible TD, Harris RA, Dowd SE, et al. (2011) Maternal methyl-donor supplementation induces prolonged murine offspring colitis susceptibility in association with mucosal epigenetic and microbiomic changes. Hum Mol Genet 20, $1687-1696$.

25. Häsler R, Feng Z, Bäckdahl L, et al. (2012) A functional methylome map of ulcerative colitis. Genome Res 22, 2130-2137.

26. Ehrich M, Nelson MR, Stanssens P, et al. (2005) Quantitative high-throughput analysis of DNA methylation patterns by base-specific cleavage and mass spectrometry. Proc Natl Acad Sci 102, 15785-15790. 
27. Lisanti S, Omar WAW, Tomaszewski B, et al. (2013) Comparison of methods for quantification of global DNA methylation in human cells and tissues. PLOS ONE 8, e79044

28. Yegnasubramanian S, Haffner MC, Zhang Y, et al. (2008) DNA hypomethylation arises later in prostate cancer progression than $\mathrm{CpG}$ island hypermethylation and contributes to metastatic tumor heterogeneity. Cancer Res 68, 8954-8967.

29. Ramsahoye BH (2002) Measurement of genome wide DNA methylation by reversed-phase high-performance liquid chromatography. Methods 27, 156-161.

30. Armstrong KM, Bermingham EN, Bassett SA, et al. (2011) Global DNA methylation measurement by HPLC using low amounts of DNA. Biotechnol J 6, 113-117.

31. Globisch D, Münzel M, Müller M, et al. (2010) Tissue distribution of 5-hydroxymethylcytosine and search for active demethylation intermediates. PLOS ONE 5, e15367.

32. Le T, Kim KP, Fan G, et al. (2011) A sensitive mass spectrometry method for simultaneous quantification of DNA methylation and hydroxymethylation levels in biological samples. Anal Biochem 412, 203-209.

33. Yamashita S, Hosoya K, Gyobu K, et al. (2009) Development of a novel output value for quantitative assessment in methylated DNA immunoprecipitation-CpG Island microarray analysis. DNA Res 16, 275-286.

34. Cokus SJ, Feng S, Zhang X, et al. (2008) Shotgun bisulphite sequencing of the Arabidopsis genome reveals DNA methylation patterning. Nature 452, 215-219.

35. Weber M, Davies JJ, Wittig D, et al. (2005) Chromosome-wide and promoter-specific analyses identify sites of differential DNA methylation in normal and transformed human cells. Nat Genet 37, 853-862.

36. Gebhard C, Schwarzfischer L, Pham TH, et al. (2006) Genomewide profiling of $\mathrm{CpG}$ methylation identifies novel targets of aberrant hypermethylation in myeloid leukemia. Cancer Res 66, 6118-6128.

37. Selker EU, Tountas NA, Cross SH, et al. (2003) The methylated component of the Neurospora crassa genome. Nature $\mathbf{4 2 2}$ 893-897.

38. Khulan B, Thompson RF, Ye K, et al. (2006) Comparative isoschizomer profiling of cytosine methylation: The HELP assay. Genome Res 16, 1046-1055.

39. Suzuki M, Jing Q, Lia D, et al. (2010) Optimized design and data analysis of tag-based cytosine methylation assays. Genome Biol 11, R36.

40. Gu H, Smith ZD, Bock C, et al. (2011) Preparation of reduced representation bisulfite sequencing libraries for genome-scale DNA methylation profiling. Nat Protoc 6, 468-481.

41. Meissner A, Gnirke A, Bell GW, et al. (2005) Reduced representation bisulfite sequencing for comparative high-resolution DNA methylation analysis. Nucleic Acids Res 33 5868-5877.

42. Meissner A, Mikkelsen TS, Gu H, et al. (2008) Genome-scale DNA methylation maps of pluripotent and differentiated cells. Nature 454, 766-770.

43. Bock C, Tomazou EM, Brinkman A, et al. (2010) Genomewide mapping of DNA methylation: a quantitative technology comparison. Nat Biotechnol 28, 1106-1114.

44. Tost J \& Gut IG (2016) Molecular techniques for DNA methylation studies. In Molecular Diagnostics, 3rd ed., pp. 103-139 [George P.Patrinos, editor]. London: Elsevier Ltd.

45. Lipka DB, Wang Q, Cabezas-Wallscheid N, et al. (2014) Identification of DNA methylation changes at cis-regulatory elements during early steps of HSC differentiation using tagmentation-based whole genome bisulfite sequencing. Cell Cycle 13, 3476-3487.
46. Rakoff-Nahoum S, Kong Y, Kleinstein SH, et al. (2015) Analysis of gene-environment interactions in postnatal development of the mammalian intestine. Proc Natl Acad Sci $\mathbf{1 1 2}$, 1929-1936.

47. Sommer F, Nookaew I, Sommer N, et al. (2015) Site-specific programming of the host epithelial transcriptome by the gut microbiota. Genome Biol 16, 62 .

48. Allan Walker W (2013) Initial intestinal colonization in the human infant and immune homeostasis. Ann Nutr Metab 63, 8-15.

49. Pan WH, Sommer F, Falk-Paulsen M, et al. (2018) Exposure to the gut microbiota drives distinct methylome and transcriptome changes in intestinal epithelial cells during postnatal development. Genome Med 10, 1-15.

50. Yu D-H, Gadkari M, Zhou Q, et al. (2015) Postnatal epigenetic regulation of intestinal stem cells requires DNA methylation and is guided by the microbiome. Genome Biol 16, 211.

51. Kraiczy J, Nayak KM, Howell KJ, et al. (2019) DNA methylation defines regional identity of human intestinal epithelial organoids and undergoes dynamic changes during development. Gut 68, 49-61.

52. Hu Y, Hu L, Gong D, et al. (2018) Genome-wide DNA methylation analysis in jejunum of Sus scrofa with intrauterine growth restriction. Mol Genet Genomics 293, 807-818.

53. Forn M, Díez-Villanueva A, Merlos-Suárez A, et al. (2015) Overlapping DNA methylation dynamics in mouse intestinal cell differentiation and early stages of malignant progression. PLOS ONE 10, e0123263.

54. Elliott EN, Sheaffer KL, Schug J, et al. (2015) Dnmt1 is essential to maintain progenitors in the perinatal intestinal epithelium. Development 142, 2163-2172.

55. Sheaffer KL, Kim R, Aoki R, et al. (2014) DNA methylation is required for the control of stem cell differentiation in the small intestine. Genes Dev 28, 652-64.

56. Mummaneni P, Yates P, Simpson J, et al. (1998) The primary function of a redundant Sp1 binding site in the mouse aprt gene promoter is to block epigenetic gene inactivation. Nucleic Acids Res 26, 5163-5169.

57. Matsuo K, Silke J, Georgiev O, et al. (1998) An embryonic demethylation mechanism involving binding of transcription factors to replicating DNA. EMBO J 17, 1446-1453.

58. Kaaij LTJ, van de Wetering M, Fang F, et al. (2013) DNA methylation dynamics during intestinal stem cell differentiation reveals enhancers driving gene expression in the villus. Genome Biol 14, R50.

59. Elliott EN, Sheaffer KL \& Kaestner KH (2016) The 'de novo' DNA methyltransferase Dnmt3b compensates the Dnmt1deficient intestinal epithelium. Elife 5, e12975.

60. Ahuja N, Li Q, Mohan AL, et al. (1998) Aging and DNA methylation in colorectal mucosa and cancer. Cancer Res 58, 5489-5494.

61. Hu B, Gharaee-Kermani M, Wu Z, et al. (2010) Epigenetic regulation of myofibroblast differentiation by DNA methylation. Am J Pathol 177, 21-28.

62. Ning Y, Huang H, Dong Y, et al. (2013) 5-Aza-2'-deoxycytidine inhibited PDGF-induced rat airway smooth muscle cell phenotypic switching. Arch Toxicol 87, 871-881.

63. Jorgensen BG, Berent RM, Ha SE, et al. (2018) DNA methylation, through DNMT1, has an essential role in the development of gastrointestinal smooth muscle cells and disease. Cell Death Dis 9, 1-14.

64. Kim R, Sheaffer KL, Choi I, et al. (2016) Epigenetic regulation of intestinal stem cells by Tet1-mediated DNA hydroxymethylation. Genes Dev 30, 2433-2442. 
65. Uribe-Lewis S, Carroll T, Menon S, et al. (2020) 5-hydroxymethylcytosine and gene activity in mouse intestinal differentiation. Sci Rep 10, 1-11.

66. Sommer F \& Bäckhed F (2013) The gut microbiota-masters of host development and physiology. Nat Rev Microbiol 11, 227-238.

67. Buchon N, Broderick NA, Chakrabarti S, et al. (2009) Invasive and indigenous microbiota impact intestinal stem cell activity through multiple pathways in Drosophila. Genes Dev 23, 2333-2344.

68. Comelli EM, Simmering R, Faure M, et al. (2008) Multifaceted transcriptional regulation of the murine intestinal mucus layer by endogenous microbiota. Genomics $\mathbf{9 1}, 70-77$.

69. Rawls JF, Mahowald MA, Ley RE, et al. (2006) Reciprocal gut microbiota transplants from zebrafish and mice to germ-free recipients reveal host habitat selection. Cell 127, 423-433.

70. Lecuit M, Sonnenburg JL, Cossart P, et al. (2007) Functional genomic studies of the intestinal response to a foodborne enteropathogen in a humanized gnotobiotic mouse model. $J$ Biol Chem 282, 15065-15072.

71. Hooper L V., Wong MH, Thelin A, et al. (2001) Molecular analysis of commensal host-microbial relationships in the intestine. Science 291, 881-884.

72. Sun J, Zhong H, Du L, et al. (2018) Gene expression profiles of germ-free and conventional piglets from the same litter. Sci Rep 8, 10745.

73. Shenderov BA (2012) Gut indigenous microbiota and epigenetics. Microb Ecol Health Dis 23. Publihed online: 28 March 2012. doi: 10.3402/mehd.v23i0.17195.

74. Richards AL, Burns MB, Alazizi A, et al. (2016) Genetic and transcriptional analysis of human host response to healthy gut microbiota. mSystems 1, e00067-e00016.

75. Buchon N, Broderick NA, Poidevin M, et al. (2009) Drosophila intestinal response to bacterial infection: activation of host defense and stem cell proliferation. Cell Host Microbe 5, 200-211.

76. Oka T, Sato H, Ouchida M, et al. (2011) Cumulative epigenetic abnormalities in host genes with viral and microbial infection during initiation and progression of malignant lymphoma/leukemia. Cancers (Basel) 3, 568-581.

77. Paschos K \& Allday MJ (2010) Epigenetic reprogramming of host genes in viral and microbial pathogenesis. Trends Microbiol 18, 439-447.

78. Aoyama M, Kotani J \& Usami M (2010) Butyrate and propionate induced activated or non-activated neutrophil apoptosis via HDAC inhibitor activity but without activating GPR-41/ GPR-43 pathways. Nutrition 26, 653-661.

79. Delage B \& Dashwood RH (2008) Dietary manipulation of histone structure and function. Annu Rev Nutr $\mathbf{2 8}$ 347-366.

80. Eden S, Hashimshony T, Keshet I, et al. (1998) DNA methylation models histone acetylation. Nature 394, 842.

81. Kau AL, Ahern PP, Griffin NW, et al. (2011) Human nutrition, the gut microbiome, and immune system: envisioning the future. Nature $\mathbf{4 7 4}, 327-336$

82. Pan X, Thymann T, Gao F, et al. (2020) Rapid gut adaptation to preterm birth involves feeding-related DNA methylation reprogramming of intestinal genes in pigs. Front Immunol 11, 565 .

83. Ansari I, Raddatz G, Gutekunst J, et al. (2020) The microbiota programs DNA methylation to control intestinal homeostasis and inflammation. Nat Microbiol 5, 610-619.

84. Takahashi K, Sugi Y, Nakano K, et al. (2011) Epigenetic control of the host gene by commensal bacteria in large intestinal epithelial cells. J Biol Chem 286, 35755-35762.
85. Bhat MI, Kumari A, Kapila S, et al. (2019) Probiotic lactobacilli mediated changes in global epigenetic signatures of human intestinal epithelial cells during Escherichia coli challenge. Ann Microbiol 69, 603-612.

86. Million M, Diallo A \& Raoult D (2017) Gut microbiota and malnutrition. Microb Pathog 106, 127-138.

87. Castaner O, Goday A, Park Y-M, et al. (2018) The gut microbiome profile in obesity: a systematic review. Int JEndocrinol 2018, 4095789.

88. Blanton L V., Barratt MJ, Charbonneau MR, et al. (2016) Childhood undernutrition, the gut microbiota, and microbiota-directed therapeutics. Science 352, aad9359-2.

89. Singh RK, Chang HW, Yan D, et al. (2017) Influence of diet on the gut microbiome and implications for human health. $J$ Transl Med 15. Published online: 08 April 2017. https://doi. org/10.1186/s12967-017-1175-y

90. Iizumi T, Battaglia T, Ruiz V, et al. (2017) Gut microbiome and antibiotics. Arch Med Res 48, 727-734.

91. Wang B, Yao M, Lv L, et al. (2017) The human microbiota in health and disease. Engineering 3, 71-82.

92. Krautkramer KA, Kreznar JH, Romano KA, et al. (2016) Dietmicrobiota interactions mediate global epigenetic programming in multiple host tissues. Mol Cell 64, 982-992.

93. Zhang N, Ju Z \& Zuo T (2018) Time for food: the impact of diet on gut microbiota and human health. Nutrition 51-52, 80-85.

94. Jiménez-Chillarón JC, Díaz R, Martínez D, et al. (2012) The role of nutrition on epigenetic modifications and their implications on health. Biochimie 94, 2242-2263.

95. Mudd SH, Brosnan JT, Brosnan ME, et al. (2007) Methyl balance and transmethylation fluxes in humans. Am J Clin Nutr 85, $19-25$.

96. Stover PJ (2011) Polymorphisms in 1-carbon metabolism, epigenetics and folate-related pathologies. $J$ Nutrigenet Nutrigenomics 4, 293-305.

97. Van den Veyver IB (2002) Genetic effects of methylation diets. Annu Rev Nutr 22, 255-282.

98. Kominsky DJ, Keely S, Macmanus CF, et al. (2011) An endogenously anti-inflammatory role for methylation in mucosal inflammation identified through metabolite profiling. $J$ Immunol 186, 6505-6514.

99. Ingrosso D, Cimmino A, Perna AF, et al. (2003) Folate treatment and unbalanced methylation and changes of allelic expression induced by hyperhomocysteinaemia in patients with uraemia. Lancet 361, 1693-1699.

100. Lucas A (1998) Programming by early nutrition: an experimental approach. J Nutr 128, 401S-406S.

101. Vansant G (2016) Effect of maternal and paternal nutrition on DNA methylation in the offspring: a systematic review of human and animal studies. Adv Obesity Weight Manag Control 4, 81-97.

102. Waterland RA \& Jirtle RL (2004) Early nutrition, epigenetic changes at transposons and imprinted genes, and enhanced susceptibility to adult chronic diseases. Nutrition 20, 63-68.

103. Persad VL, Hof MC Van Den, Dubé JM, et al. (2002) Incidence of open neural tube defects in Nova Scotia after folic acid fortification. Can Med Assoc J 167, 241-245.

104. Hajj N El, Schneider E, Lehnen H, et al. (2014) Epigenetics and life-long consequences of an adverse nutritional and diabetic intrauterine environment. Reproduction 148, R111-R120.

105. Laker RC, Wlodek ME, Connelly JJ, et al. (2013) Epigenetic origins of metabolic disease: The impact of the maternal condition to the offspring epigenome and later health consequences. Food Sci Hum Wellness 2, 1-11.

106. Yang X, Huang Y, Sun C, et al. (2017) Maternal prenatal folic acid supplementation programs offspring lipid metabolism by aberrant DNA methylation in hepatic ATGL and adipose LPL in 
rats. Nutrients 9. Published online: 26 August 2017. doi: 10 3390/nu9090935.

107. Tain Y-L, Chan J, Lee C-T, et al. (2018) Maternal melatonin therapy attenuates methyl-donor diet-induced programmed hypertension in male adult rat offspring. Nutrients 10 Published online: 2 October 2018. doi: 10.3390/nu10101407.

108. Skjærven KH, Jakt LM, Fernandes JMO, et al. (2018) Parental micronutrient deficiency distorts liver DNA methylation and expression of lipid genes associated with a fatty-liver-like phenotype in offspring. Sci Rep 8. Published online: 14 February 2018. https://doi.org/10.1038/s41598-018-21211-5.

109. Keleher MR, Zaidi R, Shah S, et al. (2018) Maternal high-fat diet associated with altered gene expression, DNA methylation, and obesity risk in mouse offspring. PLOS ONE $\mathbf{1 3}$ e0192606.

110. Alves da Silva A V, de Castro Oliveira SB, Di Rienzi SC, et al. (2019) Murine methyl donor deficiency impairs early growth in association with dysmorphic small intestinal crypts and reduced gut microbial community diversity. Curr Dev Nutr 3, nzy070.

111. Choi SW, Friso S, Ghandour H, et al. (2004) Vitamin B-12 deficiency induces anomalies of base substitution and methylation in the DNA of rat colonic epithelium. J Nutr 134, 750-755.

112. McKay JA, Waltham KJ, Williams EA, et al. (2011) Folate depletion during pregnancy and lactation reduces genomic DNA methylation in murine adult offspring. Genes Nutr $\mathbf{6}$, 189-196.

113. Lillycrop KA, Phillips ES, Jackson AA, et al. (2005) Dietary protein restriction of pregnant rats induces and folic acid supplementation prevents epigenetic modification of hepatic gene expression in the offspring. J Nutr 135, 1382-1386.

114. Lillycrop KA, Phillips ES, Torrens C, et al. (2008) Feeding pregnant rats a protein-restricted diet persistently alters the methylation of specific cytosines in the hepatic PPAR $\alpha$ promoter of the offspring. Br J Nutr 100, 278-282.

115. McKay JA, Wong YK, Relton CL, et al. (2011) Maternal folate supply and sex influence gene-specific DNA methylation in the fetal gut. Mol Nutr Food Res 55, 1717-1723.

116. Ly L, Chan D, Aarabi M, et al. (2017) Intergenerational impact of paternal lifetime exposures to both folic acid deficiency and supplementation on reproductive outcomes and imprinted gene methylation. Mol Hum Reprod 23, 461-477.

117. Mir SA, Nagy-Szakal D, Dowd SE, et al. (2013) Prenatal methyl-donor supplementation augments colitis in young adult mice. PLOS ONE 8, e73162.

118. Trasler J, Deng L, Melnyk S, et al. (2003) Impact of Dnmt1 deficiency, with and without low folate diets, on tumor numbers and DNA methylation in min mice. Carcinogenesis 24, 39-45.

119. Pogribny IP, Ross SA, Wise C, et al. (2006) Irreversible global DNA hypomethylation as a key step in hepatocarcinogenesis induced by dietary methyl deficiency. Mutat Res Fundam Mol Mech Mutagen 593, 80-87.

120. Pogribny IP, Karpf AR, James SR, et al. (2008) Epigenetic alterations in the brains of Fisher 344 rats induced by long-term administration of folate/methyl-deficient diet. Brain Res 1237, $25-34$.

121. Ly A, Ishiguro L, Kim D, et al. (2016) Maternal folic acid supplementation modulates DNA methylation and gene expression in the rat offspring in a gestation period-dependent and organ-specific manner. J Nutr Biochem 33, 103-110.

122. Zeng H, Yan L, Cheng W-H, et al. (2011) Dietary selenomethionine increases exon-specific DNA methylation of the p53 gene in rat liver and colon mucosa. J Nutr 141, $1464-1468$.
123. Tapp HS, Commane DM, Bradburn DM, et al. (2013) Nutritional factors and gender influence age-related DNA methylation in the human rectal mucosa. Aging Cell 12, 148-155.

124. Remely M, Ferk F, Sterneder S, et al. (2017) EGCG prevents high fat diet-induced changes in gut microbiota, decreases of DNA strand breaks, and changes in expression and DNA methylation of Dnmt1 and MLH1 in C57BL/6J male mice. Oxid Med Cell Longev 2017, 3079148.

125. Morris J, Moseley VR, Cabang AB, et al. (2016) Reduction in promotor methylation utilizing EGCG (epigallocatechin-3gallate) restores RXR $\alpha$ expression in human colon cancer cells. Oncotarget 7, 35313-35326.

126. Unno T, Sakuma M \& Mitsuhashi S (2014) Effect of dietary supplementation of (-)-epigallocatechin gallate on gut microbiota and biomarkers of colonic fermentation in rats. J Nutr Sci Vitaminol (Tokyo) 60, 213-219.

127. Kevin Day J, Bauer AM, Desbordes C, et al. (2002) Genistein alters methylation patterns in mice. $J$ Nutr 132, 2419S-2423S.

128. Guerrero-Bosagna CM, Sabat P, Valdovinos FS, et al. (2008) Epigenetic and phenotypic changes result from a continuous pre and post natal dietary exposure to phytoestrogens in an experimental population of mice. BMC Physiol 8, 17.

129. Rees WD, Hay SM, Brown DS, et al. (2000) Maternal protein deficiency causes hypermethylation of DNA in the livers of rat fetuses. J Nutr 130, 1821-1826.

130. Coupé B, Amarger V, Grit I, et al. (2010) Nutritional programming affects hypothalamic organization and early response to leptin. Endocrinology 151, 702-713.

131. Straten EME van, Bloks VW, Huijkman NCA, et al. (2010) The liver X-receptor gene promoter is hypermethylated in a mouse model of prenatal protein restriction. AJP Regul Integr Comp Physiol 298, R272-R274.

132. Burdge GC, Hanson MA, Slater-Jefferies JL, et al. (2007) Epigenetic regulation of transcription: a mechanism for inducing variations in phenotype (fetal programming) by differences in nutrition during early life? Br J Nutr 97, 1036-1046.

133. Lillycrop KA, Slater-Jefferies JL, Hanson MA, et al. (2007) Induction of altered epigenetic regulation of the hepatic glucocorticoid receptor in the offspring of rats fed a proteinrestricted diet during pregnancy suggests that reduced DNA methyltransferase- 1 expression is involved in impaired DNA methylation and. Br J Nutr 97, 1064-1073.

134. Burdge GC, Lillycrop KA, Phillips ES, et al. (2009) Folic acid supplementation during the juvenile-pubertal period in rats modifies the phenotype and epigenotype induced by prenatal nutrition. J Nutr 139, 1055-1060.

135. Martínez D, Pentinat T, Ribó S, et al. (2014) In utero undernutrition in male mice programs liver lipid metabolism in the second-generation offspring involving altered Lxra DNA methylation. Cell Metab 19, 941-951.

136. Heo HJ, Tozour JN, Delahaye F, et al. (2016) Advanced aging phenotype is revealed by epigenetic modifications in rat liver after in utero malnutrition. Aging Cell 15, 964-972.

137. Carone BR, Fauquier L, Habib N, et al. (2010) Paternallyinduced transgenerational environmental reprogramming of metabolic gene expression in mammals Benjamin. Cell 143, 1084-1096.

138. Altmann S, Murani E, Schwerin M, et al. (2012) Somatic cytochrome c (CYCS) gene expression and promoter-specific DNA methylation in a porcine model of prenatal exposure to maternal dietary protein excess and restriction. Br J Nutr 107, 791-799. 
139. Sandovici I, Smith NH, Nitert MD, et al. (2011) Maternal diet and aging alter the epigenetic control of a promoter-enhancer interaction at the Hnf4a gene in rat pancreatic islets. Proc Natl Acad Sci 108, 5449-5454.

140. Nätt D, Barchiesi R, Murad J, et al. (2017) Perinatal malnutrition leads to sexually dimorphic behavioral responses with associated epigenetic changes in the mouse brain. Sci Rep 7, 11082.

141. Bogdarina I, Welham S, King PJ, et al. (2007) Epigenetic modification of the renin-angiotensin system in the fetal programming of hypertension. Circ Res 100, 520-526.

142. Bogdarina I, Haase A, Langley-Evans S, et al. (2010) Glucocorticoid effects on the programming of AT1b angiotensin receptor gene methylation and expression in the rat. PLOS ONE 5, e9237.

143. Coupé B, Amarger V, Grit I, et al. (2010) Nutritional programming affects hypothalamic organization and early response to leptin. Endocrinology 151, 702-713.

144. Claycombe KJ, Uthus EO, Roemmich JN, et al. (2013) Prenatal low-protein and postnatal high-fat diets induce rapid adipose tissue growth by inducing Igf2 expression in Sprague Dawley rat offspring. J Nutr 143, 1533-1539.

145. Jousse C, Parry L, Lambert-Langlais S, et al. (2011) Perinatal undernutrition affects the methylation and expression of the leptin gene in adults: implication for the understanding of metabolic syndrome. FASEB J 25, 3271-3278.

146. Radford EJ, Ito M, Shi H, et al. (2014) In utero undernourishment perturbs the adult sperm methylome and intergenerational metabolism. Science 345, 1255903.

147. Ivanova E, Chen JH, Segonds-Pichon A, et al. (2012) DNA methylation at differentially methylated regions of imprinted genes are resistant to developmental programming by maternal nutrition. Epigenetics 7, 1200-1210.

148. Altmann S, Murani E, Schwerin M, et al. (2013) Dietary protein restriction and excess of pregnant German Landrace sows induce changes in hepatic gene expression and promoter methylation of key metabolic genes in the offspring. $J$ Nutr Biochem 24, 484-495. Elsevier.

149. Jia Y, Li R, Cong R, et al. (2013) Maternal low-protein diet affects epigenetic regulation of hepatic mitochondrial DNA transcription in a sex-specific manner in newborn piglets associated with GR binding to its promoter. PLOS ONE 8, e63855.

150. Wang J, Cao M, Yang M, et al. (2016) Intra-uterine undernutrition amplifies age-associated glucose intolerance in pigs via altered DNA methylation at muscle GLUT4 promoter. $\mathrm{Br}$ J Nutr 116, 390-401.

151. Unterberger A, Szyf M, Nathanielsz PW, et al. (2009) Organ and gestational age effects of maternal nutrient restriction on global methylation in fetal baboons. J Med Primatol 38, 219-227.

152. Nijland MJ, Mitsuya K, Li C, et al. (2010) Epigenetic modification of fetal baboon hepatic phosphoenolpyruvate carboxykinase following exposure to moderately reduced nutrient availability. I Physiol 588, 1349-1359.

153. Heijmans BT, Tobi EW, Stein AD, et al. (2008) Persistent epigenetic differences associated with prenatal exposure to famine in humans. Proc Natl Acad Sci 105, 17046-17049.

154. Waterland RA, Kellermayer R, Laritsky E, et al. (2010) Season of conception in rural gambia affects DNA methylation at putative human metastable epialleles. PLOS Genet 6, e1001252.

155. Tobi EW, Slieker RC, Luijk R, et al. (2018) DNA methylation as a mediator of the association between prenatal adversity and risk factors for metabolic disease in adulthood. Sci $A d v$, eaao4364.

156. Einstein F, Thompson RF, Bhagat TD, et al. (2010) Cytosine methylation dysregulation in neonates following intrauterine growth restriction. PLOS ONE 5, e8887.

157. Tobi EW, Lumey LH, Talens RP, et al. (2009) DNA methylation differences after exposure to prenatal famine are common and timing- and sex-specific. Hum Mol Genet 18, 4046-4053.

158. Weng X, Zhou D, Liu F, et al. (2014) DNA methylation profiling in the thalamus and hippocampus of postnatal malnourished mice, including effects related to long-term potentiation. BMC Neurosci 15. Published online: 20 February 2014. doi: 10.1186/1471-2202-15-31.

159. Peter CJ, Fischer LK, Kundakovic M, et al. (2016) DNA Methylation signatures of early childhood malnutrition associated with impairments in attention and cognition. Biol Psychiatry 80, 765-774.

160. Narayan J \& Dangi CBS (2017) Study on prevalence of global DNA methylation preceded due to malnutrition in schoolage- children of Bhopal and adjoining areas. Int J Sci Res $\mathbf{6}$, 767-773.

161. Klutstein M, Nejman D, Greenfield R, et al. (2016) DNA methylation in cancer and aging. Cancer Res 76, 3446-3450.

162. Vaquero A \& Reinberg D (2009) Calorie restriction and the exercise of chromatin. Genes Dev 23, 1849-1869.

163. Li Y, Liu L \& Tollefsbol TO (2010) Glucose restriction can extend normal cell lifespan and impair precancerous cell growth through epigenetic control of hTERT and p16 expression. FASEB J 24, 1442-1453.

164. Wilson VL, Smith RA, Mag S, et al. (1987) Genomic 5-methyldeoxycytidine decreases with age. $J$ Biol Chem 262, 9948-9951.

165. Issa JPJ, Ottaviano YL, Celano P, et al. (1994) Methylation of the oestrogen receptor $\mathrm{CpG}$ island links ageing and neoplasia in human colon. Nat Genet 7, 536-540.

166. Issa J-PJ (1996) Switch from monoallelic to biallelic human IGF2 promoter methylation during aging and carcinogenesis. Proc Natl Acad Sci 93, 11757-11762.

167. Waki T, Tamura G, Sato M, et al. (2003) Age-related methylation of tumor suppressor and tumor-related genes: an analysis of autopsy samples. Oncogene 22, 4128-4133.

168. Waki T, Tamura G, Sato M, et al. (2003) Promoter methylation status of DAP-kinase and RUNX3 genes in neoplastic and nonneoplastic gastric epithelia. Cancer Sci 94, 360-364.

169. Maegawa S, Lu Y, Tahara T, et al. (2017) Caloric restriction delays age-related methylation drift. Nat Commun $8,539$.

170. Vucetic Z, Kimmel J, Totoki K, et al. (2010) Maternal high-fat diet alters methylation and gene expression of dopamine and opioid-related genes. Endocrinology 151, 4756-4764.

171. Ramamoorthy TG, Allen TJ, Davies A, et al. (2018) Maternal overnutrition programs epigenetic changes in the regulatory regions of hypothalamic Pomc in the offspring of rats. Int $J$ Obes 42, 1431-1444.

172. Dudley KJ, Sloboda DM, Connor KL, et al. (2011) Offspring of mothers fed a high fat diet display hepatic cell cycle inhibition and associated changes in gene expression and DNA methylation. PLOS ONE 6, e21662.

173. Zhang Y, Wang H, Zhou D, et al. (2015) High-fat diet caused widespread epigenomic differences on hepatic methylome in rat. Physiol Genomics 47, 514-523.

174. Seki Y, Suzuki M, Guo X, et al. (2017) In utero exposure to a high-fat diet programs hepatic hypermethylation and gene dysregulation and development of metabolic syndrome in male mice. Endocrinology 158, 2860-2872. 
175. Sharp GC, Salas LA, Monnereau C, et al. (2017) Maternal BMI at the start of pregnancy and offspring epigenome-wide DNA methylation: findings from the pregnancy and childhood epigenetics (PACE) consortium. Hum Mol Genet 26, 4067-4085.

176. Borengasser SJ, Zhong Y, Kang P, et al. (2013) Maternal obesity enhances white adipose tissue differentiation and alters genome-scale DNA methylation in male rat offspring. Endocrinology 154, 4113-4125.

177. Li CCY, Young PE, Maloney CA, et al. (2013) Maternal obesity and diabetes induces latent metabolic defects and widespread epigenetic changes in isogenic mice. Epigenetics 8, 602-611.

178. Moody L, Chen H \& Pan Y-X (2017) Postnatal diet remodel hepatic DNA methylation in metabolic pathways established by a maternal high-fat diet. Epigenomics $9,1387-1402$.

179. Ng S-F, Lin RCY, Laybutt DR, et al. (2010) Chronic high-fat diet in fathers programs $\beta$-cell dysfunction in female rat offspring. Nature 467, 963-936.

180. Qin Y, Roberts JD, Grimm SA, et al. (2018) An obesity-associated gut microbiome reprograms the intestinal epigenome and leads to altered colonic gene expression. Genome Biol 19, 7.

181. Bouchard L, Thibault S, Guay S-P, et al. (2010) Leptin gene epigenetic adaptation to impaired glucose metabolism during pregnancy. Diabetes Care 33, 2436-2441.

182. Soubry A, Schildkraut JM, Murtha A, et al. (2013) Paternal obesity is associated with IGF2 hypomethylation in newborns: results from a Newborn Epigenetics Study (NEST) cohort. BMC Med 11, 29.

183. Vucetic Z, Kimmel J \& Reyes TM (2011) Chronic high-fat diet drives postnatal epigenetic regulation of-opioid receptor in the brain. Neuropsychopharmacology 36, 1199-1206.

184. Plagemann A, Harder T, Brunn M, et al. (2009) Hypothalamic proopiomelanocortin promoter methylation becomes altered by early overfeeding: An epigenetic model of obesity and the metabolic syndrome. J Physiol 587, 4963-4976.

185. Plagemann A, Roepke K, Harder T, et al. (2010) Epigenetic malprogramming of the insulin receptor promoter due to developmental overfeeding. J Perinat Med, 393-400.

186. Sayols-Baixeras S, Subirana I, Fernández-Sanlés A, et al. (2017) DNA methylation and obesity traits: An epigenomewide association study. The REGICOR study. Epigenetics 12, 909-916.

187. Rzehak P, Covic M, Saffery R, et al. (2017) DNA-methylation and body composition in preschool children: epigenomewide-analysis in the European childhood obesity project (CHOP)-study. Sci Rep 7, 14349.

188. Lopez-Pedrosa JM, Torres MI, Fernandez MI, Rios A, Gill A (1998) Severe malnutrition alters lipid composition and fatty acid profile of small intestine in newborn piglets. $J$ Nutr 128, 224-233.

189. Garas LC, Feltrin C, Hamilton MK, et al. (2016) Milk with and without lactoferrin can influence intestinal damage in a pig model of malnutrition. Food Funct 7, 665-678. 